\title{
DESCRIPTION OF A WROUGHT-IRON CONSTRUCTION OF OBSERVATORY, FOR MAINTAINING EQUALITY OF INTERNAL AND EXTERNAL TEMPERATURE.
}

By Mr. CHARLES CLEMENT WALKER, of Donninfton.

The construction of an Observatory is required to be such as to afford complete protection to the telescope when not in use, and at the same time to maintain it in perfect condition for use whenever desired ; and the latter point is of special importance in this country, in consequence of the opportunities for astronomical observation being so few in comparison with the numerous nights that are unfavourable for the purpose. In order to obtain the correct performance of the telescope, it is requisite for the temperature of the surrounding air inside the observatory to be the same as that of the external air, so that no local currents of air may be set up when the doors are put open for observation; because the accuracy of definition of the telescope is seriously impaired when the light suffers irregular refraction throngh currents of air of different densities, such as occur when a difference of temperature exists in the surrounding air. This is especially the case with reflecting telescopes, on account of the air being free to move within the open tube of the instrument; and reflecting telescopes are so much affected by this cause that they can seldom be used satisfactorily except in the open air ; and the difficulty experienced in constructing observatories free from air currents has checked the use of reflecting telescopes, notwithstanding their great advantage in moderate cost as compared with the very great cost of refracting telescopes of corresponding size.

The desideratum is therefore to obtain the convenience and advantage of an observatory, in a building that will keep the telescope in the same condition as if in the open air. For this purpose it is required that the walls of the building should offer so 
little obstruction to the passage of heat through them that the temperature inside may follow at once all changes in the temperature of the external air ; and to attain this object, it is necessary not only that the walls should be good conductors so as to transmit the heat rapidly, but also that the whole amount of heat stored up in the mass of the walls should be so small as to produce little effect in retarding the corresponding change of temperature inside the building, whenever a change takes place in the temperature of the external air. A thorough and continuous communication with the external air by free rentilation is also requisite.

The special point is to secure this equilibrium of temperature in the air during the evening and night, the time when the telescope is generally wanted for use; so that when the doors are opened for using the telescope, there may be an entire freedom from disturbing currents of air of different temperatures and densities. The great difficulty has been to get rid of the day's heat in preparation for the night's use of the observatory; and in the ordinary construction with thick walls of slowly conducting materials, several hours are found to elapse before equilibrium of temperature is restored after any long exposure to the direct rays of the sun in the daytime, owing not only to the large amount of heat taken up by the material of the building, which has to be all dispersed, but also to the slow rate of transmission of the heat through the walls. Fven a construction of thin boards or canvas requires a considerable time to restore equilibrium of temperature after a hot day, when a difference of temperature of $40^{\circ} \mathrm{Fahr}$. between day and night is of common occurrence.

As an attempt to remove this difficulty, a Wrought-Iron Observatory has been constructed by the writer, in which his idea has been to employ no material in the building except a good conductor of heat, and to obtain sufficient strength with a very small thickness and total mass of material. This building, which is shown in Figs. 1 to 5, Plates 81 to 83, is constructed entirely of wrought iron, with thin sides and top, and light angle-iron framing riveted together. In Plates 81 and 82 are shown an elevation and plan 
of the observatory when closed and when opened; and in Plate 83 is a vertical section to a larger scale. This observatory has proved thoroughly successful in maintaining uniformity of temperature with the external air ; and in the evenings and nights (when this is specially required) the internal and external temperatures are found to be exactly the same or within $\frac{1}{2}^{\circ}$, although the heating effect of the previous mid-day sun may have been very great.

In the usual construction of observatory the top only is made to revolve for giving the telescope a view in all directions, and the axis of the telescope is then required to be above the level of the side walls in order to obtain horizon views; but this involves the inconvenience of using high steps to reach the eye-piece, and requires an increased height of dome. The writer determined therefore in the present observatory to make the whole building turn round; and this allowed the adoption of an octagon shape as more convenient for construction in wrought iron, and preferable to a circular form in the general external appearance and finish of such a building.

The telescope A, Plate 83, for which it is constructed, is a $10 \frac{1}{4}$ inch reflector, with silvered glass speculum of 6 feet focal length, and equatorially mounted; the pillar is bolted down upon a stone and brick pier $B$, about 2 feet square and 5 feet deep, which is kept quite free and isolated from the joists and boards of the floor. A clear space of $\frac{1}{2}$ inch is left all round the pier, and the isolation is so complete that not the least vibration is perceived in the telescope even with a high power, from any amount of shaking of the floor. The circular rail $\mathrm{C}$ upon which the building revolves is fixed down upon a wood cill on a ring of brickwork, and is cast in segments with the ends tongued together. This rail has teeth cast upon the outer side, 1 inch pitch, as shown to a larger scale in Figs. 8 and 9, Plate 84, making a fixed circular rack of $11 \frac{1}{2}$ feet diameter, into which gears a pinion $\mathrm{D}$ of $2 \frac{3}{4}$ inches diameter, for turning the building round by a hand winch $\mathrm{E}$.

The building is an octagon, 12 feet diameter inside, with sides 7 feet high, and a sloping roof flat in the centre, as shown in Plates 81 and 82 ; and it is constructed with a framing of $2 \frac{1}{2}$ inch 
angle-iron at the bottom and the angles of the sides, covered with sheet iron of 18 wire-gauge and flush-riveted. Each side is in four sheets, with a flat bar riveted over their junction, forming them into neat panels; and two opposite sides are made to open as a pair of doors. For zenith views with the telescope, a pair of doors in the flat top are opened, giving a range of $23^{\circ}$ on each side of the zenith; two pairs of doors in the slope of the roof give a view to $60^{\circ}$ from the zenith on each side, and the main side doors give the view to the horizon. The roof doors are readily opened from the inside by quadrant-shaped handles, which have holes and pins to keep them open or closed; and the whole or any portion may be opened as desired, so as to expose the observer to as little external cold as possible. In order to get the rain water off the flat centre of the roof, a small cover slide on the sloping roof doors is pushed up when these are closed, as shown in Fig. 7, Plate 84, and is drawn down when they are opened, that the sloping doors may then clear the centre ones.

The sides of the observatory have an opening of 4 inches width all round under the eaves, as shown in Fig. 5 ; and an opening $\frac{1}{2}$ inch wide is left all round at the bottom beyoud the edge of the fixed floor, giving clearance for revolving the observatory; by these means free ventilation is constantly maintained. No rain can enter at these openings; and it is only required to provide flaps for closing the upper opening in the case of snow, to prevent its drifting in. The roof doors are protected from entrance of rain by a tongue and cover strip along their meeting edges, as shown at $\mathrm{F}$ in Fig. 6, Plate 84. The building is moved round upon the circular rail by a pair of bevil wheels G, Fig. 8, driving the pinion D that gears into the circular rack; the whole is carried on 4 inch flanged wheels $\mathrm{H}$ fixed upon brackets on the bottom angle-iron, and can be turned round with the greatest ease by the hand winch $\mathrm{E}$. When the observatory is fully open for observing through the whole range from zenith to horizon, as shown in Plate 82, the three top bars $K$ which cross the opening are taken down, being made removable for the purpose; and as the building is thereby cut in half at that point, any tendency to spread out is prevented by first putting a 
connecting bar $\mathrm{L}$ with a tightening screw across the door opening, below the horizon level of the telescope.

The result of two and a half years' working of this observatory has been completely satisfactory. However rapid or sudden the changes of external temperature may be, the interual temperature is found to follow so quickly that the difference does not exceed $2^{\circ}$, and is generally found to be less than $1^{\circ}$, at the time of opening the observatory for use. However great may have been the extent of heating of the building by exposure to the sun during the day, the internal temperature in the evening is found to be practically the same as that of the external air, with the building still closed; so that when opened for use, the telescope is found already in the same condition as if standing in the open air, and does not require any interval for cooling before being in proper condition for use.

The following are two examples of the results with a falling temperature in the outside air, the inside temperature being taken by a thermometer hanging free in the centre of the observatory :-

$\begin{array}{ccccc}\text { Time } & 3.0 \text { p.m. } & 7.5 \mathrm{p} . \mathrm{m} . & 8.5 \mathrm{p} . \mathrm{m} . & 11.0 \mathrm{p} . \mathrm{m} . \\ \text { Inside temperature } & 71^{\circ} & 49^{\circ} & 47^{\circ} & 45^{\circ} \\ \text { Outside temperature } & - & 47 \frac{1}{2}^{\circ} & 45^{\circ} & 45^{\circ}\end{array}$

Time 3.10 p.m. 6.15 p.m. 7.45 p.m. 8.45 p.m. 9.45 p.m.

$\begin{array}{llllll}\text { Inside temperature } & 76^{\circ} & 61^{\circ} & 58^{\circ} & 59^{\circ} & 57 \frac{1}{2}^{\circ} \\ \text { Outside temperature } & - & 60 \frac{1}{2}^{\circ} & 58^{\circ} & 59^{\circ} & 57 \frac{1}{2}^{\circ}\end{array}$

These examples show that, even with so great a fall of temperature as $26^{\circ}$ from day to night, an equilibrium of temperature between the internal and external air is maintained throughout the evening within $2^{\circ}$. These results are confirmed by numerous observations made under various circumstances, and indicating a difference of temperature generally of less than $1^{\circ}$; and also showing how closely the observatory follows the temperature of the external air at the critical time of sunset.

The following is an example of a rising temperature in the outside air by a change in the night after sunset, and shows an equilibrium maintained throughout:- 


\begin{tabular}{lccc}
\multicolumn{1}{c}{ Time } & $7 \cdot 0 \mathrm{p} . \mathrm{m}$. & $10.0 \mathrm{p} . \mathrm{m}$. & $7 \cdot 45 \mathrm{a.m}$. \\
Inside temperature & $45^{\circ}$ & $47^{\circ}$ & $54^{\circ}$ \\
Outside temperature & $45^{\circ}$ & $47^{\circ}$ & $54^{\circ}$
\end{tabular}

In all the above cases the thermometer for measuring the temperature of the external air was hanging free, away from any building, and protected from the heat of the direct rays when the sun was shining; but when exposed to the sun the walls of the observatory become heated above the temperature of the external air, and the internal air is consequently raised in temperature, as shown in the following example:-

$\begin{array}{cccc}\text { Time } & 9.30 \mathrm{a.m} . & 1.0 \mathrm{p.m} . & 2.30 \mathrm{p.m} . \\ \text { Inside temperature } & 66^{\circ} & 73^{\circ} & 72^{\circ} \\ \text { Outside exposed thermometer } & 70^{\circ} & 81^{\circ} & 75^{\circ} \\ \text { Outside temperature in shade } & 55^{\circ} & 62^{\circ} & 63^{\circ}\end{array}$

The outside exposed thermometer was upon the wall of the observatory, and showed an excess of temperature of $12^{\circ}$ to $19^{\circ}$ above the external air in the shade, with an excess of $9^{\circ}$ to $11^{\circ}$ in the temperature of the internal over the external air.

A building of slowly conducting material, such as brick, stone, or wood, has an apparent advantage in such cases, in retarding this heating effect upon the internal air, in consequence of the transmission of heat through the walls being slower. The rapidity of transmission in the case of the iron observatory is not however any practical disadvantage, for as the occasions of using the telescope in the daytime are for observation of the sun, the building can then be thrown open, protection from the weather being not then required; and the heating of the internal air by a closed building is thus obviated. The rapidity of transmission of heat through the walls of the iron observatory is on the contrary the point of special value in its construction, as this provides for its rapid cooling down after the withdrawal of the sun's direct rays; the excess of heat is thus quickly dissipated, and the equilibrium of temperature restored between the inside and outside air.

As a test of the rapidity of transfer of the heat and recovery of equilibrium of temperature, it may be mentioned that when the observatory is exposed to the direct rays of the sun, and then 
suddenly screened by a cloud passing over, causing a fall of temperature in the external exposed thermometer, the temperature inside begins to follow in about three minutes, falling as rapidly as $4^{\circ}$ in five minutes; and when the external temperature continues uniform for as long as ten minutes, the internal thermometer comes within less than $1^{\circ}$ of the external air. Whatever small differences of temperature occur between the internal and the external air seem due to the constant variations in the temperature of the external air. An illustration of the effect produced by the use of slow conducting material in retarding the rate of cooling has been afforded by a wood drawer containing books within the observatory, which is found to retain a portion of the mid-day heat so long, that in the evening the temperature within the drawer is $10^{\circ}$ higher than the air within the building, whilst the latter has at the time the same temperature as the external air. Also in the morning, in a rising temperature after a cold night, the air in the observatory is assimilated so rapidly to the open air, that the heavy mass of the telescope pillar, though iron, becomes covered with moisture, from not having followed the rise of temperature of the air; while the observatory and telescope continue perfectly dry.

The President observed that the object of this wrought-iron construction of observatory was not to maintain the same temperature inside as outside during the daytime while the sun was shining, which might be impracticable; but to have a building which after sunset would rapidly assume the temperature of the external air, so that when required for use the telescope should be in the same condition as if standing in the open air.

Mr. F. BIRD enquired whether after a severe frost the walls of the observatory kept dry, and whether the silvered mirror of the telescope ever became coated with dew at such a time. In other 
observatories there was generally a great deposition of moisture upon the walls and instrument after frosty weather.

$\mathrm{Mr}$. WALKER replied that, whenever the external air was so thick with moisture that all outside was covered with dew, the interior of the observatory was of course affected in the same manner as if in the open air, when standing open for use. The deposition of moisture within the building when closed could be prevented to a large extent by closing the shutters all round the eaves; this however was not intended to be done ordinarily, because the object was merely to screen the observer from the weather, while securing the same temperature and state of atmosphere within the building as in the open air. The moisture coming in with the external air did not interfere at all with the observations, nor was there ever more moisture inside than outside. After a continued severe frost, in observatories constructed of brick, stone, or other non-conducting materials, the thickness of the walls stored up so much cold, and it took so long a time for the returning warmth of the weather to penetrate them, that the moisture in the air was condensed upon them to such an extent that they streamed with water, and kept the telescope in the same condition, often for several days, till equilibrium of temperature was restored. He knew of cases where the water deposited had to be baled up from the floor, and also poured off the face of the speculum. Nothing of the kind ever happened with the iron observatory, the walls of which stored up no cold, because they were so thin; and whatever alteration took place in the external air, the internal air partook of it at once, and consequently no moisture was condensed; and since it had been constructed, the telescope had never been hindered from immediate use by deposition of moisture, even after the most severe weather. In the morning, with a rising temperature after a cold night, while the walls of the observatory remained perfectly dry, be had known the iron pillar of the telescope become covered with moisture when the sun began to shine, in consequence of the rapid rise of temperature in the air, which was followed much more slowly by the mass of iron in the pillar. In the same way the metal of the telescope holding 
the speculum followed the rise of temperature more slowly than the air in the building, and continued at first $3^{\circ}$ or $4^{\circ}$ colder than the air; there was consequently sometimes a slight film of moisture upon the surface of the speculum for a few minutes in the morning when the sun began to shine, but this disappeared as soon as ever the speculum was exposed to the sun. In the daytime, whilst exposed to the direct rays of the sun, the walls of the building, like all other solid opaque objects, became of course heated to a much higher temperature than the surrounding transparent air; and consequently the air within the building then became heated considerably above the outside air, to the extent of as much as $11^{\circ}$ higher in the observations recorded in the paper; but it would be noticed that at that time there had been no less a difference than $19^{\circ}$ between the external temperature in the shade and in the sun.

Mr. C. E. Amos remarked that the internal temperature of $73^{\circ}$ in that instance was nearly a mean between the two external temperatures of $62^{\circ}$ in the shade and $81^{\circ}$ in the sunshine.

The Presidext enquired whether the exposed thermometer was placed against a wall exposed to the sun, or was hung exposed to the sun at a distance from any solid object; this would materially affect the result of the observation.

Mr. WALKER replied that the exposed thermometer was bung about an inch from the iron wall of the observatory, directly facing the sun. The temperature of the internal air was seen to follow regularly that of the external air, continuing about a mean between the external temperatures in the sun and in the shade.

Mr. F. BIRD asked what was about the cost of an observatory like that described in the paper.

Mr. WALKER replied that at the present time the cost would probably be about $£ 75$, but it would depend upon the price of iron. A wooden building might be a little less expensive, but considering the efficiency and general advantages of the iron construction he thought it was preferable. The octagonal shape was not at all objectionable in appearance, and was more convenient for an iron structure than a circular form, which also he thought would not have looked so well. 
The President enquired what was the weight of the revolving portion of the observatory, and how much heavier it was than the revolving dome in an ordinary building for a telescope of the same size.

Mr. WALKER said the revolving weight was about 15 or 16 cwts., which was about double the weight of the revolving dome in an ordinary observatory of that size. The building could be pushed round by hand, but was rotated with the greatest readiness by the hand winch as being so much easier and more convenient.

The President enquired what was the reason for mounting the observatory upon cylindrical flanged wheels, which involved the friction of the flanges against the rail, as well as the friction arising from the cylindrical wheels having to run in a circle; conical wheels appeared a more correct form for travelling round the circular rail.

Mr. WALKER said that conical wheels required a fixed centre to revolve round, in order to keep their path, and this was inadmissible in an observatory. The flanged wheels kept the revolving building truly central, and the rail being rounded on the top, the surface of contact of the cylindrical wheels was so small that very little resistance was offered to their running in a circle, the flanges also being bevilled so as to touch the rail to the least extent possible. The whole resistance to revolving the observatory was so small that a child could turn it round easily by means of the winch handle.

Mr. A. PAGET remarked that, as the revolving portion of the observatory could not be allowed to touch the centre pillar, a set of vertical guide rollers would have been required for preventing conical wheels from running off the rail, if flanges had not been used, which would have been an increase of expense without an equivalent advantage; and he thought the friction of the flanged wheels, though of course greater than the friction of the conical wheels, must be so slight as to be practically immaterial when a child could turn the observatory round with the flanged wheels.

The President considered the iron construction of observatory now described was an interesting application of mechanical 
contrivance to a scientific purpose, and judiciously carried out. $\mathrm{He}_{\mathbf{e}}$ moved a vote of thanks to $M r$. Walker for his paper, which was passed.

The Meeting then terminated. 
WROUGHT - IRON OBSERVATORY. Plate 81.

Fig: 1. Elevation, when closed.

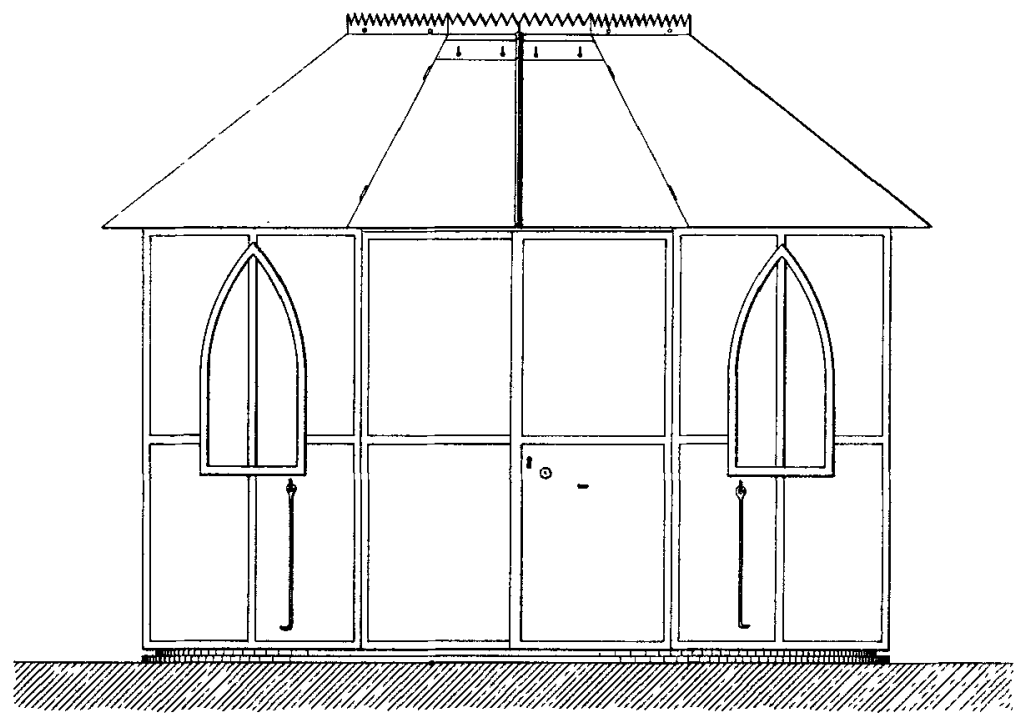

Fig. 2. Sectional Plan

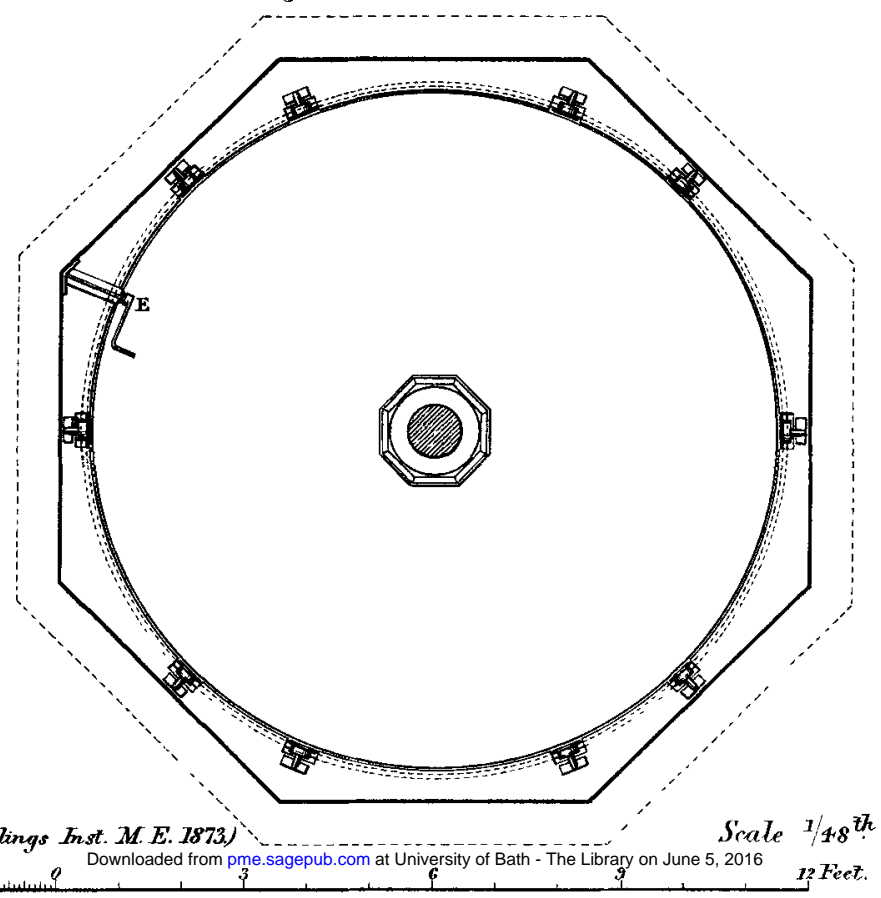



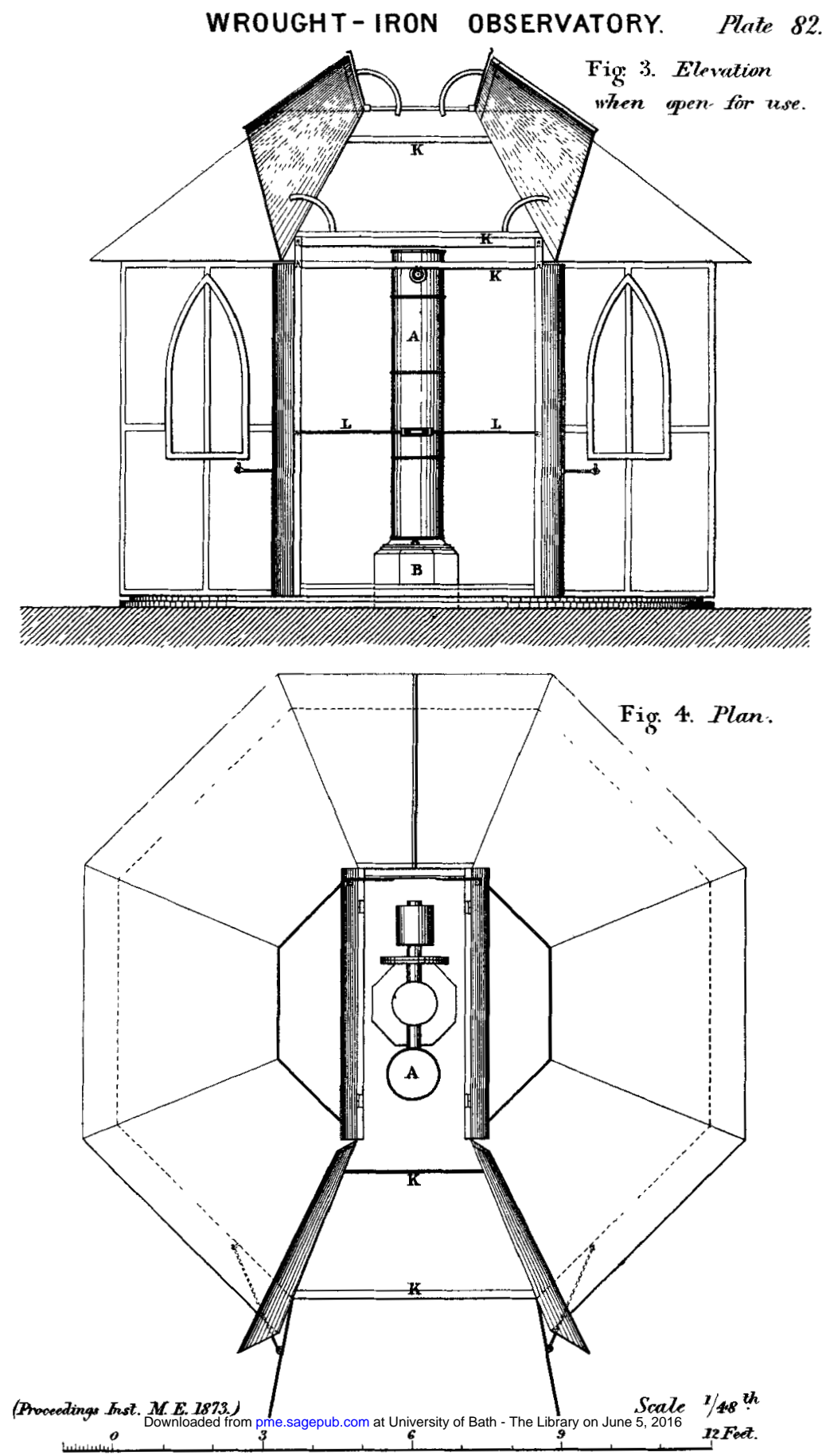
Fig: 5. Tertical Section.

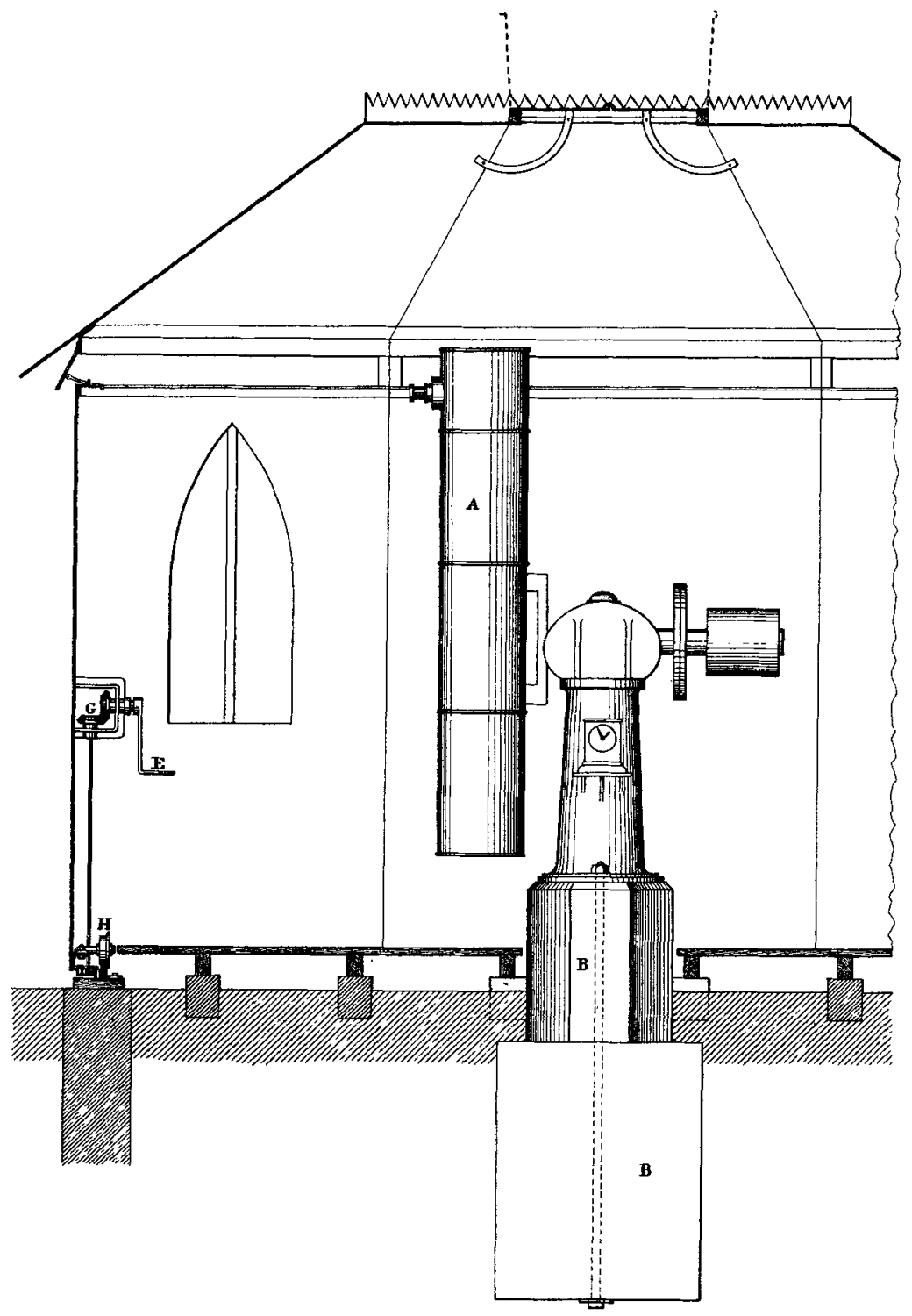

(Provedings Hst. M. E. 3873.)

Scale 1/30 th.

Ins. 72 Downloaded from pme.saggepub.com at University of Bath - The Library on June 5, 2016 $s$ Feet. 
WROUGHT - IRON OBSERVATORY. Plate s4.

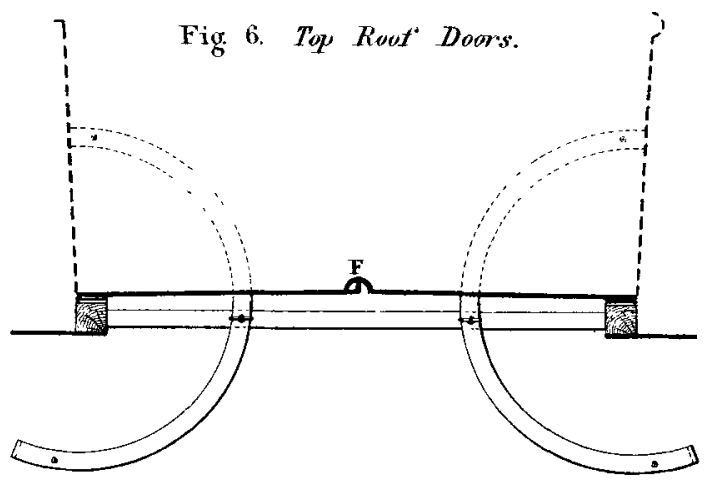

Fig: 7.

Cover stide.

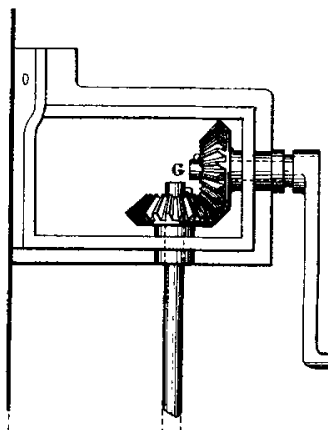

Fig. 8.

Elevation of Tuming Gear

for rotating the Observatory.

Stationary Floor.
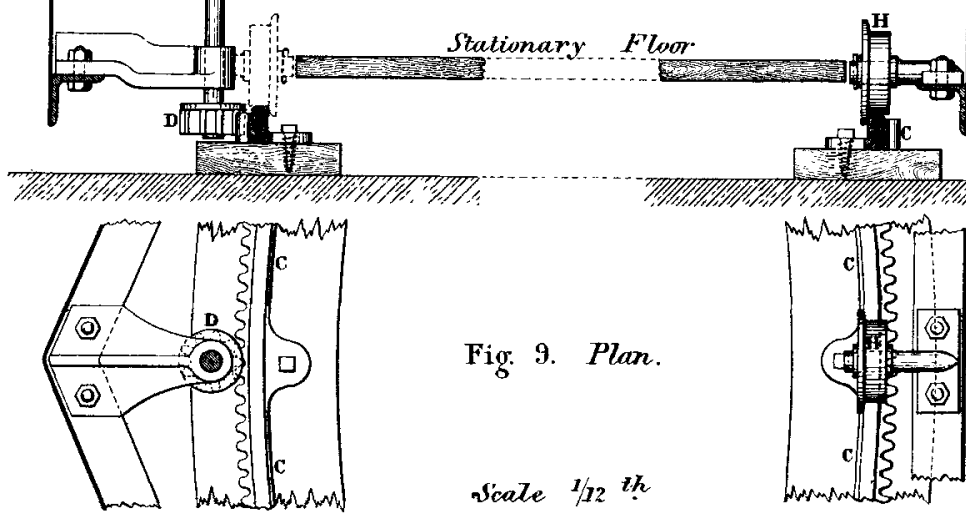

Fig: 9. Plan.

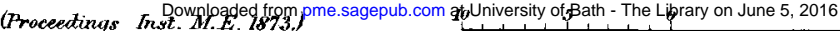

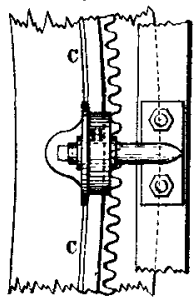

